\title{
Caste, Ethnicity and Poverty in Rural India
}

\author{
Ira N. Gang \\ Department of Economics, Rutgers University \\ gang@economics.rutgers.edu \\ Kunal Sen \\ School of Development Studies, University of East Anglia \\ k.sen@uae.ac.uk \\ Myeong-Su Yun \\ Department of Economics, Tulane University \\ msyun@tulane.edu
}

October 2002

\begin{abstract}
This paper analyzes the determinants of rural poverty in India, contrasting the situation of the Scheduled Caste (SC) and Schedule Tribe (ST) households with the non-scheduled population. The incidence of poverty among SC and ST households is significantly higher than non-scheduled households. Using a probit decomposition analysis, we decompose the difference in the poverty rates between the scheduled castes (or tribes) and non-scheduled households into a part explained by the differences in characteristics and a part explained by the differences in probit coefficients. The paper finds that for SC households, differences in characteristics explain the gap in poverty rates more than differences in coefficients; while for ST households, it is the reverse. Differences in educational attainment explain about one quarter of the poverty gap for both social groups. Occupational structure strongly matters in determining the poverty gap for both SC and ST, as does differences in returns to individual occupations. While poverty rates are not very different between SC and ST households, the analysis suggests that the underlying factors for the higher incidence of poverty in these social groups are to a large extent different.
\end{abstract}

Keywords: poverty, caste, ethnicity, probit decomposition JEL Classifications: I32; O12;J15.

This manuscript has benefitted from discussions with Shubhashis Gangopadhyay. We thank Richard Palmer-Jones for helping us with the data.

Correspondence: Kunal Sen, School of Development Studies, University of East Anglia, Norwich NR4 7TJ, United Kingdom; email: k.sen@.uea.ac.uk. 


\section{Introduction}

One of the main goals of development is to eliminate poverty. Poverty ultimately deprives people of the capability to live decent and healthy lives and of the opportunities to develop their potential to the maximum. Fighting poverty has been a primary goal of advancing the welfare of individuals in less developed countries. The Indian government has also been deeply concerned with widespread poverty and implemented several anti-poverty schemes in the past. However, rural poverty remains stubbornly persistent, with the headcount ratio being 42.7 per cent in 1993/94 (Dubey and Gangopadhyay 1998). More troubling is the concentration of rural poverty in India in the 'scheduled caste' (SC) and 'scheduled tribe'( ST) population. Though striking, it may not be surprising, since the scheduled groups have historically faced discrimination. ${ }^{1}$ Since 1950 , affirmative action programs have been at the core of Indian social policy towards the these two social groups. According to the 1991 Census of India, scheduled castes and scheduled tribes comprise 16.5 percent and 8.1 percent respectively of India's population, yet about 43.53 per cent of India's rural poor are concentrated in these two social groups. ${ }^{2}$ Poverty rates among scheduled caste and tribe households are significantly higher than the rest of the population - in 1993/1994, the

${ }^{1}$ The Indian Constitution specifies the list of castes and tribes to be included in these two categories, and accords the 'scheduled castes' and 'scheduled tribes' special treatment in terms of affirmative action quotas in state and central legislatures, the civil service and governmentsponsored educational institutions (Revankar 1971). The 'scheduled castes' correspond to the castes at the bottom of the hierarchical order of the Indian caste system and were subject to social exclusiveness in the form of 'untouchability' at Indian Independence (August 15, 1947), while the 'scheduled tribes' correspond to the indigenous tribal population mainly residing in the northern Indian states of Bihar, Gujarat, Maharashtra, Madhya Pradesh, Orissa, Rajasthan, West Bengal and in North-eastern India.

${ }^{2}$ These estimates are from the unit record data provided in the National Sample Survey's $50^{\text {th }}$ round of the consumer expenditure survey. More details of the computations are provided in the next section. 
proportion of SC and ST households below the poverty line were 49.0 and 49.5 per cent respectively, as compared to a poverty rate of 32.8 per cent for non-scheduled households. There exists a gap in the proportion living in poverty (a ' poverty gap') of 16.2 percent $(=49.0-32.8)$ between SC and non-scheduled households, and a 'poverty gap' of 16.7 percent $(=49.5-32.8)$ between ST and non-scheduled households. One major task in the fight to reduce rural poverty is, therefore, to close the gap in poverty rates between scheduled castes and tribes and the nonscheduled group.

Though the large gap in poverty rates between scheduled and non-scheduled groups may not be surprising, it is important to understand what causes the poverty gap between the scheduled and non-scheduled groups to be so large. This paper explores this issue: what explains the gap in poverty between the scheduled castes or tribes and the non-scheduled households? Specifically, we ask whether differences in the amount of schooling, occupational choice or demographic characteristics hold the key to understanding the poverty gap. Also we ask whether the poverty mitigating strength of household or individual characteristics (e.g. education and occupation) are different. To answer these questions, we first explore the poverty determinants of the scheduled households, SC and ST, and non-scheduled household, using household survey data on 64,287 households from the $50^{\text {th }}$ round of the National Sample Survey (NSS). ${ }^{3}$ This is done by estimating a probit model where the dependent variable has a value of one when a household is in poverty. In order to explain why

${ }^{3}$ Three other studies that examine the economic status of the scheduled castes and tribes are Deshpande (2000, 2001) and Meenakshi and Ray (2002). The first two studies compute measures of disparity between the scheduled castes and tribes and the non-scheduled households (and in the case of the first study, only for the state of Kerala), while the third paper studies a poverty by constructing headcount ratios for the households of the scheduled castes and tribes under different assumptions of economies of scale in consumption and equivalence scales. None of these studies examine the determinants of poverty of the scheduled castes and tribes relative to non-scheduled households. 
poverty is much more prevalent among the scheduled casts and tribes, than among the nonscheduled households, we decompose the difference in the poverty rates between the scheduled castes (or tribes) and non-scheduled households into a part explained by the differences in characteristics (characteristics effect) and a part explained by the differences in the probit coefficients (coefficient effect). The characteristics effects capture the poverty gap caused by the differences in the levels of characteristics. The disparity in the level of characteristics might result from widespread discrimination against the scheduled groups in terms of opportunity of education and choice of occupation. The coefficients effects capture the poverty gap caused by the differences in the effectiveness of the characteristics in reducing poverty between the two comparison groups.

Our methodology allows us to not only calculate the aggregate characteristics and coefficients effects, but also these effects for specific variables and groups of variables (Yun, 2000) Thus we will be able to say, for example, how much differences in schooling contribute to the gap in poverty between the groups, and how much of the gap is related to the effectiveness of the education attainment differing between the scheduled and the non-scheduled group.

The remainder of the paper is in four sections. In the next section we discuss who are the poor among the Scheduled Castes, Scheduled Tribes and the non-scheduled group by studying the mean characteristics of each group. Section 3 investigates why they are poor. Various forces have been presented in the literature as possible factors generating poverty differences among the scheduled castes and tribes and non-scheduled households. We examine poverty determinants by utilizing a probit analysis of the relative influence of various economic and non-economic variables on poverty. Section 4 employs a probit decomposition analysis to examine and explain the poverty gaps between the scheduled castes (or tribes) and non-scheduled households. Finally, Section 5 provides a summary of our study and its main conclusions. 


\section{Who are the Poor?}

The database is provided by the household survey data on consumer expenditure in rural areas collected for 25 states and 7 Union Territories in India in the $50^{\text {th }}$ round of the NSS. The survey period was July 1993 to June 1994. The NSS gives rise to unique data sets consisting of cross-sections of a geographically distributed random sample of households across India. In addition to information on household consumer expenditure and demographic behavior, the NSS contains detailed questions on other household characteristics such as the educational level and occupation of the head of the household.

In this paper, we focus on rural poverty. This is for two reasons. Firstly, the majority of India's poor live in rural areas. Secondly, the NSS classifies a household as SC or ST if it is so indicated at the time of the survey by the head of the household. Such sorting criteria as indicators of a household's social status will be weaker in urban areas where marriages between SC and ST individuals and non-scheduled individuals may occur. Since the NSS provides expenditure data by household, our estimates of poverty are at the level of the household, not at the level of the individual. ${ }^{4}$

We first present our estimates of rural poverty across all three social groups, and relate these to the demographic, educational and occupational characteristics of these three groups. Poverty rates at the official State specific poverty lines (taken from Dubey and Gangopadhyay, 1999) were obtained by enumerating the number of households with monthly per capita total expenditure below

\footnotetext{
${ }^{4}$ This distinction may become important if there are significant differences in the intrahousehold consumption of food and other necessities across the SC, ST and non-scheduled households (for example, if intrahousehold distribution is more equal for SC and ST households than non-scheduled households, then poverty at the level of the household could overestimate poverty at the level of the individual for SC and ST households).
} 
the poverty line. ${ }^{5}$ We restrict our sample to households where the age of the head of the household is between 20 and 70 years. Since the information on age, education and occupation that we obtain from the NSS surveys are for the head of the household, the range 20-70 assumes an age structure where the head of the household is expected to be economically active.

The poverty rates by social group and by age, household size, educational level and occupation are presented in Table $1 .^{6}$ Firstly, we observe that there is a non-linear relationship between age and poverty rates across all three social groups, with the poverty rate first increasing as we move from the age group 20-29 to 30-39, and then decreasing with ages 40 years and greater. Secondly, poverty rates seem to increase with household size, with the highest poverty rates observed among households that comprise 7 or more members. Thirdly, while literacy is negatively related to the incidence of poverty, the negative correlation between educational attainment and the incidence of poverty seem to be weaker for SC households as compared to ST and non-scheduled households. Around 23 per cent of SC households with literacy levels of higher secondary and above are poor as compared to 14.9 per cent of similarly educated ST households and 9.9 per cent of nonscheduled households. Finally, there is a higher incidence of poverty among agricultural laborers across all three social groups as compared to other occupations, and in the case of ST households, for those households self-employed in agriculture.

${ }^{5}$ These poverty lines were loosely based on a concept of minimum food (especially calorie) expenditure plus additional necessary expenditure. Thus, the key concept was that those households were poor that did not purchase at least 2400 calories per capita. It should be noted that poverty estimates are sensitive to the choice of the poverty line, and alternate estimates of the poverty line do exist for India. However, Dubey and Gangopadhyay (1999) show that the relative ranking of Indian regions with respect to the poverty rate is robust to the specification of the poverty line.

${ }^{6}$ All our estimates of poverty are weighted by the multiplier associated with each household provided by the data. The multiplier for each household indicate the total number of households in the population represented by the sampled household. 
Table 2 shows the mean characteristics of the sample households in our study. Considering the demographic characteristics of three groups of households first, we find that SC and ST households have a lower mean age for the head of the household as compared to non-scheduled households. SC and ST households are also smaller in size than non-scheduled households -- the mean household size for SC and ST households are 4.7 and 4.8 respectively, as compared to a mean household size of 5.0 for non-scheduled households.

A much higher proportion of SC and ST households are not literate (68 per cent and 70 per cent respectively), as compared to non-scheduled households (48 per cent of whom are not literate). With respect to occupation, 11 per cent of SC households are self-employed in non-agriculture, 53 per cent as agricultural laborers, 11 per cent as non-agricultural laborers, 19 per cent are selfemployed in agriculture while 6 per cent are classified in a residual category termed 'others'. For ST households, 6 per cent are self-employed in non-agriculture, 39 per cent are agricultural laborers, 10 per cent are non-agricultural laborers, 39 per cent are self-employed in agriculture while 6 per cent are in other occupations. Finally, for non-scheduled households, 15 per cent are self-employed in non-agriculture, 24 per cent are agricultural laborers, 7 per cent are non-agricultural laborers, 44 per cent are self-employed in agriculture while 10 per cent are in other occupations. Thus, a greater proportion of SC households are agricultural laborers as compared to ST and non-scheduled households. On the other hand, a greater proportion of ST households are employed as nonagricultural laborers, as compared to SC and non-scheduled households.

Although interesting, Table 1 is only suggestive as the observed bivariate connections may be caused by other variables. For instance, the stronger incidence of poverty among SC households vs non-scheduled households may be age-related. Or, the observations can be due to differences in the educational attainment between the older and younger generations. In order to keep other things 
constant, one must therefore carry out a multivariate analysis of the factors determining poverty status. This we do in the section below.

\section{Why are they Poor? The Determinants of Poverty}

We carry out a probit analysis of poverty. In the probit analysis, the probability of observing a household in poverty is defined as Prob(in poverty $=1)=M(X \$)$, where $M$ is a standard normal

cumulative distribution function, $\$$ is a set of estimated coefficients and $X$ includes various explanatory variables to be specified below.

The focus of our analysis is on education and occupation. To capture the effect of education on the probability of a household being in poverty, we use dummy variables corresponding to the highest educational level completed by the head of the household. Thus, we include dummy variables corresponding to 'literate, below primary level', 'literate, below secondary level', 'literate up to secondary level', and 'literate, higher secondary and above' (the reference group in our case are households where the head of the household is not literate). With respect to occupation, we include dummy variables corresponding to four occupational groups - self-employed in nonagriculture, self-employed in agriculture, agricultural labor and non-agricultural labor (with the reference group being the occupational category termed 'others' by the NSS).

In addition to the explanatory variables capturing occupation and educational levels, we include in our analysis a number of background and demographic variables. First, we include the generational impact reflected by the age of the person. We use two variables: AGE (number of years), and AGESQUARE (number of years of age squared divided by 100), to reflect decreasing or increasing effects of age on poverty. Second, we incorporate the effect of household size (HOUSEHOLD SIZE) on the probability of the household being in poverty, as previous studies have 
noted a negative relationship between per capita expenditures and the size of the household (Krishnaji 1980, 1984; Lipton and Ravallion 1995). Given the possible presence of economies of scale in household consumption, we also include household size squared as an additional control variable. $^{7}$

Finally, we include controls for the location of the household. There are large differences in rural poverty rates within Indian states, with states in North-western India (Haryana, Punjab) along with the state of Kerala having lower poverty rates than the national average (Datt and Ravallion 1998, 2002). In contrast, the poverty rates in Assam, Bihar and Orissa are significantly higher than the national average. The omission of state dummies to capture the location of the household may bias the results if the SC and ST households are mostly residing in the states where higher poverty is observed, and if this higher incidence of poverty is due to state-level factors exogenous to the household such as agro-climactic factors or the nature of state-level public policies towards poorer households. We present our results with and without the inclusion of state dummies.

The estimated probit coefficients are reported in Table 3, with columns (1), (3) and (5) containing the results for SC, ST and non-scheduled households without the inclusion of state dummies. Columns (2), (4) and (6) contain the results with the state dummies. The dependent variable is a binary variable with a value of one if the household is in poverty. We first note that the results are not sensitive to the inclusion of state dummies, with the reported coefficients for each of the independent variables broadly similar across all three social groups. The estimated coefficients show that greater educational attainment is associated with a statistically significant reduction in the probability of being poor, with everything else held constant. This is true for all

${ }^{7} \mathrm{We}$ do not include the child adult ratio which is often used a control for household composition as inter-group poverty comparisons using NSS data seem to be quite robust to different assumptions on equivalence scales (Dreze and Srinivasan 1997, Meenakshi and Ray 2002). 
three groups of households. However, higher educational attainment from the secondary level up seems to lead to a greater decline in the incidence of poverty among ST and non-scheduled households as compared to SC households.

We now turn our attention to occupation and its role in poverty status. The results on this issue reported in Table 3 are consistent and robust. Compared to the occupational category 'others', all other occupational categories lead to a higher incidence of poverty among all three social groups (except in the case of non-scheduled households who are self-employed in agriculture when state dummies are included). SC households who are agricultural laborers are more likely to be in poverty compared to agricultural laborer households in the other two social groups. In the case of ST households, those who are self-employed in agriculture are more likely to be in poverty than SC and non-scheduled households in the same occupational group. Overall, the results suggest that there is a poverty bias among households who are laborers, whether involved in agricultural or nonagricultural work, when compared to households who are self-employed.

With respect to demographic factors, we find that higher age of the head of the household is associated with lower poverty. However, this relationship is non-linear, with further increases in age leading to less than proportionate decrease in poverty. A similar non-linear relationship exists between poverty and household size. While poverty is more evident in larger sized households, economies of scale in consumption imply that with increases in household size, the incidence of poverty is proportionately less. ${ }^{8}$

The results of the probit models imply that households which are larger in size, and households where the head of the household is not literate, is an agricultural laborer, and is younger

${ }^{8}$ The presence of economies in scale in consumption is a well-established feature of household expenditure data in India and other developing countries (see Lanjouw and Ravallion 1993, Dreze and Srinivasan 1997 and Meenakshi and Ray 2002). 
in age are more likely to be in poverty. We also find that there are differences in the effects of different explanatory variables on the likelihood of a household being poor. For example, agricultural laborer households who belong to the SC social group are more likely to be in poverty that agricultural laborer households belonging to the ST and non-scheduled social groups. However, it is not clear whether the large poverty gaps that can be observed between SC and non-scheduled households, or ST and non-scheduled households can be attributed to differences in these coefficients. Alternately, the 'poverty gaps' could be explained by the differences in characteristics between these social groups. We examine the role of characteristics and their coefficients in determining the observed 'poverty gaps' between SC and non-scheduled households, and between ST and non-scheduled households, in the section below.

\section{Analyzing the Poverty Gap: A Decomposition Analysis}

In this section, we seek to explain why poverty is much more prevalent among the scheduled caste and tribe households, than among non-scheduled households. We are measuring poverty by the poverty rate, defined to be the number of households below the poverty line as a proportion of total number of households, and we refer to the difference in the poverty rate between the scheduled castes and non-scheduled, and between the scheduled tribes and non-scheduled, as the poverty gap. That is, for the scheduled castes in comparison to non-scheduled we are seeking to explain a poverty gap of $16.2(=49.0-32.8)$; for scheduled tribes versus non-scheduled the gap is $16.7(=49.5-32.8)$. Our analysis breaks down the poverty gap into its components.

Previous studies on poverty decomposition start with an aggregate measure of poverty for the population and examines how this measure varies for subgroups of the population. Our approach differs from the previous poverty decomposition. We are looking at poverty gap and how can we 
decompose it into components in order to gain an understanding of what accounts for it. There are two broad approaches to explaining the gap in poverty. One relies on the possibility that characteristics of individuals give rise to poverty, and that these differ among groups. For instance, one group may have less education than another group, or be in the "bad" jobs. We describe this type of explanation as a characteristics effect, because it reflects how differences in the characteristics of individuals among groups affect the likelihood that someone is in poverty.

Suppose, on the other hand, that individual characteristics were not different between two comparing groups. A second approach to explaining the poverty gap relies on the possibility that the effects of the given individual characteristics vary among the three groups. For instance, education may be less effective in reducing the probability of being poor in scheduled households relative to non-scheduled households. This suggests that differences in poverty among the groups is not due to the level of the characteristics they possess, but rather to the fact that the effectiveness of the characteristics may differ among the groups. In terms of our probit analysis in Table 3, this type of explanation is reflected in differences in coefficients estimates in the probit equations among the groups. We refer to it as a coefficients effect.

\subsection{Probit Decomposition Methodology}

Algebraically, the changes between groups $A$ and $B$ in the average probability of being poor $\left(\bar{P}_{A}-\bar{P}_{B}\right)$, where $A=$ scheduled castes or tribes and $B=$ non-scheduled, may be decomposed into two components which represent the characteristics effect and coefficients effect. Asymptotically, this is, ${ }^{9}$

${ }^{9}$ A decomposition equation with a different parameterization is also possible. The results of the other version of the decomposition equation are available from the authors upon request. 


$$
\bar{P}_{A}-\bar{P}_{B}=\left(\overline{\Phi\left(\sum_{i=1}^{i=k} X_{A}^{i} \beta_{B}^{i}\right)}-\overline{\Phi\left(\sum_{i=1}^{i=k} X_{B}^{i} \beta_{B}^{i}\right)}\right)+\left(\overline{\Phi\left(\sum_{i=1}^{i=k} X_{A}^{i} \beta_{A}^{i}\right)}-\overline{\Phi\left(\sum_{i=1}^{i=k} X_{A}^{i} \beta_{B}^{i}\right)}\right),
$$

where $M$ is standard normal cumulative distribution function, $\$_{A}$, and $\$_{B}$ are sets of estimated coefficients for each year, and $X_{A}$ and $X_{B}$ include the mean values of the various explanatory variables used in the probit equations.

The above decomposition provides us with the overall coefficient and characteristics effects. In order to find the relative contribution of each variable to the poverty gap, in terms of characteristics and coefficients effects, we employ a decomposition equation for the probit model of the following type as proposed by Yun (2000);

$$
\begin{aligned}
\bar{P}_{A}-\bar{P}_{B} & =\sum_{i=1}^{i=k} W_{\Delta X}^{i}\left(\overline{\Phi\left(\sum_{i=1}^{i=k} X_{A}^{i} \beta_{B}^{i}\right)}-\overline{\Phi\left(\sum_{i=1}^{i=k} X_{B}^{i} \beta_{B}^{i}\right)}\right) \\
& +\sum_{i=1}^{i=k} W_{\Delta \beta}^{i}\left(\overline{\Phi\left(\sum_{i=1}^{i=k} X_{A}^{i} \beta_{A}^{i}\right)}-\overline{\Phi\left(\sum_{i=1}^{i=k} X_{A}^{i} \beta_{B}^{i}\right)}\right)
\end{aligned}
$$

where

$$
W_{\Delta X}^{i}=\frac{\left(\bar{X}_{A}^{i}-\bar{X}_{B}^{i}\right) \beta_{B}^{i} \phi\left(\sum_{i=i}^{i=k} \bar{X}_{B}^{i} \beta_{B}^{i}\right)}{\sum_{i=1}^{i=k}\left(\bar{X}_{A}^{i}-\bar{X}_{B}^{i}\right) \beta_{B}^{i} \phi\left(\sum_{i=i}^{i=k} \bar{X}_{B}^{i} \beta_{B}^{i}\right)} \text { and } W_{\Delta \beta}^{i}=\frac{\bar{X}_{A}^{i}\left(\beta_{A}^{i}-\beta_{B}^{i}\right) \phi\left(\sum_{i=i}^{i=k} \bar{X}_{A}^{i} \beta_{A}^{i}\right)}{\sum_{i=1}^{i=k} \bar{X}_{A}^{i}\left(\beta_{A}^{i}-\beta_{B}^{i}\right) \phi\left(\sum_{i=i}^{i=k} \bar{X}_{A}^{i} \beta_{A}^{i}\right)},
$$

where $\mathrm{N}$ is a standard normal probability density function. ${ }^{10}$

${ }^{10}$ Because of non-linearity of the standard normal cumulative distribution function, two types of approximation have been used to find the weights $\left(W_{\Delta X}^{i}, W_{\Delta \beta}^{i}\right):(1)$ an approximation of the value of average of the standard normal distribution function, $\overline{\Phi\left(\sum_{i=1}^{i=k} X^{i} \beta^{i}\right)}$, with that of standard normal distribution evaluated at average value of exogenous variables, $\Phi\left(\sum_{i=1}^{i=k} \bar{X}^{i} \beta^{i}\right)$; (2) a Taylor expansion of $\Phi\left(\sum_{i=1}^{i=k} \overline{X_{A}^{i}} \beta_{B}^{i}\right)$ about $\overline{X_{A}^{i}} \beta_{B}^{i}=\overline{X_{A}^{i}} \beta_{A}^{i}$ or $\overline{X_{A}^{i}} \beta_{B}^{i}=\overline{X_{B}^{i}} \beta_{B}^{i}$ [for details, see Yun(2000)]. 


\subsection{Analysis}

All of the decompositions in Tables 4-7 are based on results in Table 3 of the probit analysis which are used in decomposition equations stated above. For each variable or sets of variables, each table has an estimate reported along with the percentage share. We will confine our discussion to the percentage share. The percentage share tells us what percentage of the total poverty gap is accounted for by that particular element or group of elements. The aggregate characteristics effect, for example, tells us the percentage of the poverty gap that is accounted for by the different groups possessing different levels of characteristics; in other words, that the distribution of characteristics differs among the groups. Our discussion will discuss the overall effects first, and then breakdown the overall effects in successively smaller subgroups. We discuss the 'poverty gap' of scheduled castes relative to the non-scheduled in Tables 4 and 6 , and that of scheduled tribes relative to the non-scheduled in Table 5 and 7 . In Tables 4 and 5 we find the results of the aggregate breakdown, and of key groups of variables, both when we do not include state dummies and when we do. In Tables 6 and 7 we decompose further into individual variables effects. We proceed by first discussing the aggregate effects and sub-aggregate effects without state dummies for SC households respectively. (Table 4).

The Aggregate Effects row in the tables shows the overall effects of characteristics versus coefficients in explaining differences in poverty. The majority (58 percent) of the difference in poverty is explained by the differences in the levels of characteristics possessed by the two groups, while 42 percent by the differences in probit coefficients between SC and non-scheduled. One could refer to the latter as difference in effectiveness since they represent the difference in the strength of 
the various individual characteristics influencing poverty. ${ }^{11}$ If in both groups the various variables influencing poverty status had the same strength (their coefficients in the probit equation had been equal), then 42 percent of the increased probability of being in poverty for SC households would disappear. On the other hand, if both groups had the same level distribution of characteristics, 58 percent of the of the poverty gap would disappear. When we include state dummies, the aggregate effects do not change much, with the coefficients effect being 43.7 percent and the characteristics effect being 56.3 percent. Thus, the higher poverty rate observed among SC households is not because of their location - that is, they are not located more in the poorer states in India.

In Table 4 we also see the breakdown of characteristics and coefficients effects into important variable groupings. First and foremost we see the importance of both the characteristics and the coefficients effects for occupation in determining the poverty gap. The former contributes 42.7 per cent to the poverty gap, while the latter contributes 46.4 per cent. One of the salient features of the caste system is the generally undesirable and low-paying jobs people are allowed to undertake. This would explain the characteristics effect, as SC households generally are in lessremunerative occupations. If anthropological evidence about the lack of job choice for individuals belonging to scheduled castes is accurate, this may represent a pre-market discrimination (Srinivas

${ }^{11}$ The coefficients effect in the well-known Blinder-Oaxaca decomposition of the wage gap is conventionally considered as discrimination (Blinder 1973, Oaxaca 1973). The coefficients effect in the decomposition analysis of the binary choice model may be interpreted as discrimination or behavioral differences, among other interpretations. We interpret the coefficients effect as the differences in effectiveness of characteristics to reduce poverty. Since the probit models estimate the probability of being in poverty, a positive value of coefficients effect implies that the strength of poverty reducing power of a characteristics in the scheduled groups is less strong than that of the non-scheduled group. Note that a positive value in the characteristics effect may also reflect discrimination in broad sense, if the opportunities for obtaining human capital (e.g., education) and other characteristics themselves are limited due to the discrimination. 
1962, Beteille 1965). ${ }^{12}$ At the same time the coefficients effect tells us that even if the distribution of jobs was the same between SC and non-scheduled households, SC households are being rewarded less than non-scheduled households for the same occupation (controlling for education and demographic characteristics). Or, there is a difference in the strength of poverty reducing effect between SC and non-scheduled households that puts more SC households into poverty. Though the sizes of the effects are somewhat less, we also find strong characteristics and coefficients effects for the occupational distribution when state dummies are included. Education is remarkable in that both with and without state dummies the coefficients effect is negligible, while the characteristics effect is 21-22 percent. SC households simply attain lower levels of schooling, and that puts them at greater risk of being poor. ${ }^{13}$ Age and household size are included as control variables, but the results are interesting in and of themselves. The coefficients effect of age structure (age and age squared taken together) is negative, while the characteristics effect is positive. For household size we find the characteristics effect is negative, and the coefficients effect is positive. Household size differences reduce the poverty gap, but differences in coefficients increase the poverty gap. ${ }^{14}$ The constant term also contributes to reducing the poverty gap. The constant term may reflect underlying differences between the two groups which are not captured by the other explanatory variables.

${ }^{12}$ Such discrimination may be an 'equilibrium trap' where those who break caste customs suffer economically (Akerlof 1976).

${ }^{13}$ This is supported by the finding of Dreze and Kingdon (2001) that SC and ST children are less likely to go to school, even after controlling for household wealth, parental education and motivation, school quality, and related variables.

${ }^{14}$ As seen in Table 2, SC and ST households are smaller in size than non-scheduled households, and the probit analysis suggests that the likelihood of being poor is positively related to household size. 
In Table 5 we see the results of the decomposition for scheduled tribes versus the nonscheduled households. About 41 percent of the poverty gap is explained by differences in households' characteristics between the two groups. This means that if ST an non-scheduled had have the same characteristics, then the poverty gap would have been 41 percent less. Differences in educational attainment accounts for $22.5 \%$ of the poverty gap. The occupational distribution explains $19.7 \%$ of the higher poverty among the ST households as compared to non-scheduled. These results are basically the same when state dummies are included.

59 percent of the poverty gap of 16.7 percent between ST and non-scheduled is explained by the differences in probit coefficients between ST and non-scheduled households. If in both groups the various variables influencing poverty status had the same strength (their coefficients in the probit equation had been equal), then about 59 percent of the increased probability of being in poverty for ST vis a vis non-scheduled households would disappear.

Among the various coefficient effects, it is remarkable that the coefficient of educational attainment is negative between for ST than non-scheduled. This means that the strength of the ameliorating impact of education on poverty is greater for ST than non-scheduled households. ${ }^{15}$ The coefficients effect of the occupational distribution group of variables is large between ST and nonscheduled, accounting for 53 percent of the difference in probability of being in poverty. This suggests that for ST households, more than occupational structure, what has contributed to the greater incidence of poverty among such households has been the significantly lower returns they have received for the jobs they hold as compared to non-scheduled households.

With respect to demographic control variables, as in the case of SC households, for ST

${ }^{15}$ This finding should be interpreted with some caution as it only accounts for -1.7 percent of the poverty gap between ST and non-scheduled, and with state dummies included it becomes slightly positive. 
households the coefficient effect of age structure (age and age squared taken together) is negative. Thus, the age structure of ST households is better for reducing poverty than that of non-scheduled households. This helped to reduce poverty incidence, but clearly not enough to compensate for the rest of the coefficients effects. Household size, both excluding and including state dummies, has a high positive coefficients effects and about -5 percent characteristics effects. The constant term also contributes significantly to reducing the effect of the poverty gap.

The inclusion of state dummies provides some interesting results. In the case of SC households, we had seen that with the inclusion of state dummies, both characteristics and coefficients effects are more or less the same. However, in the case of ST households, $26 \%$ of the difference in poverty rates is explained by differences in characteristics with the inclusion of state dummies, as compared to a $41 \%$ characteristics effect when state dummies are not included. These results may imply that ST households are more likely to be located in states where the average poverty rate is low (such as the north-eastern states of India). Thus, for households in this social group, location is working to the advantage of these households in reducing the 'poverty gap'.

Tables 6 and 7 present further decompositions, now with more disaggregated effects. In Table 6 we have SC versus non-scheduled, while in Table 7 we have ST versus non-scheduled. For both of these tables we restrict ourselves to the situation where we have excluded the state dummies. We find that the coefficients effect of various degree of literacy is quite small, while the characteristics effect is substantial. This underlines the importance of obtaining higher level of education for scheduled castes and tribes as it is the gap in the education attainment between the scheduled and non-scheduled groups, and not the effectiveness of education in poverty reduction, that is one of the major causes of the poverty gap.

We also find that in the case of SC households, being an agricultural laborer matters both 
in characteristics and coefficients, and explains much of the effect of occupational structure we have observed in Table 4. For ST households, while being an agricultural laborer contributes to the characteristics effect of occupational structure, the coefficient effect of the latter can be largely explained by 'self-employed in agriculture'. This is an interesting finding, as we have already observed in Table 1 that the self-employed in agriculture (i.e., cultivators) have the lowest poverty rate among all occupational types, after the category 'others'. Thus, the coefficient effect of 'selfemployed in agriculture' in increasing the poverty gap may indicate strong institutional impediments that ST households face in cultivating their land, possibly linked to underlying weaknesses in technology adoption.

\section{Summary and Conclusions}

This paper has examined the relative significance of some of the key forces that shaping the poverty profiles of the Scheduled Castes (SC), Scheduled Tribes (ST) and non-scheduled households in India. These profiles vary significantly among these three groups. While there is little difference in the incidence of poverty between SC and ST households; poverty rates of SC and ST households are 16.2 percentage points and 16.7 percentage points higher than non-scheduled households. Our analysis decomposes the poverty gap between SC and non-scheduled households, and between ST and non-scheduled households using household survey data from the $43^{\text {rd }}$ round of the National Sample Survey conducted in 1993-1994.

There are two broad approaches to explaining the poverty gap. One relies on the possibility that the characteristics of individuals that give rise to differences in poverty. We describe this type of explanation as a characteristics effect. A second approach relies on the possibility that the effects 
of the given individual characteristics on poverty gap may differ across the scheduled and nonscheduled groups. This type of effect is associated with differences in the coefficients of the probit equations among the groups, and we may refer to it as a coefficients effect.

The decomposition analysis indicates that for SC households, differences in characteristics explain the poverty gap more than differences in coefficients, with 58 percent of the poverty gap attributable to the former. For ST households, however, it is the reverse, with 59 percent of the poverty gap attributable to the differences in coefficients. We also see that differences in educational attainment explains about one quarter of the poverty gap for both social groups. Occupational structure strongly matters in determining the poverty gap for both SC and ST, as does the effect of the structure; however, the coefficient effect is relatively larger for ST households than for SC households. Among demographic factors, we find that household size is working in the favor of SC and ST households, with differences in age structure having little effect on the poverty gap. Using state dummies to capture the effect of household location on the poverty gap, we find that the large poverty gap between SC and non-scheduled households cannot be attributed to where these households are located. On the other hand, for ST households, they seem to be located in the states with lower poverty on average so that differences in characteristics have a smaller effect on the poverty gap when state dummies are introduced.

Further disaggregated analysis shows that being literate matters for reducing the poverty gap; the disparity in educational attainments between the scheduled and the non-scheduled groups causes substantial gap in the poverty rates. With respect to occupation, there is a clear difference between SC and ST households. In the case of SC households, the higher incidence of poverty among these households is both due to the higher proportion of such households who are agricultural laborers, and the lower returns they obtain from agricultural labor as compared to non-scheduled households. 
In the case of ST households, a large proportion of the poverty gap can be explained by the lower returns they receive as cultivators as compared to non-scheduled households.

The analysis of this paper has important implications for policies that can combat the significant economic deprivation that is observed among SC and ST households as compared to the rest of the population. Firstly, policies should aim at the higher educational attainments among SC and ST households; such policies should generally aim to increase the enrollment of SC and ST children, especially focusing on the primary and secondary level rather than on higher education, and preventing the high drop out rate that is evident in the school-age population in India (PROBE, 1999). It is clear from our analysis that greater amounts of literacy even below the primary schooling level will have a significant impact in reducing the poverty gap for both SC and ST households. Our analysis also suggests that in the case of SC households, policies that allow such households greater occupational choice, and in particular, diversification away from agricultural labor may pay significant poverty reduction dividends among these households (policies that encourage selfemployment among SC households may be successful in this regard). Further, there is also a need to redress the lower returns that SC households seem to obtain from agricultural labor as compared to the non-scheduled households (possibly via stricter observance of minimum wage legislations). In the case of ST households, policies need to address the lower returns these households receive from cultivation as compared to the non-scheduled cultivators. This could be in the form of targeted agricultural extension services, input subsidy programs, and directed rural credit programs. Finally, the analysis of the paper suggests that while poverty rates are not very different between SC and ST households, the underlying factors for the higher incidence of poverty in these social groups are to an appreciable extent different, and policy-makers need to be aware of these differences in the causes of poverty while devising policies for poverty alleviation. 


\section{REFERENCES}

Akerlof, G. (1976), "The Economics of Caste and the Rat Race and Other Woeful Tales", Quarterly Journal of Economics, Vol. 90, pp. 600-617.

Beteille, A. (1965), Caste, Class and Power: Changing Patterns of Social Stratification in a Tanjore Village, Berkeley: University of California Press.

Blinder, A. (1973), "Wage Discrimination: Reduced Form and Structural Estimates", Journal of Human Resources, Vol. 8, No. 4, pp. 436-455.

Deshpande, A. (2000), "Does Caste Still Define Disparity? A Look at Inequality in Kerala, India", American Economic Review, Vol. 90, No. 2, pp. 322-325.

Deshpande, A. (2001), "Caste at Birth? Redefining Disparity in India", Review of Development Economics, Vol. 5, No. 1, pp. 130-144.

Dreze, J. and P.V. Srinivasan (1997), "Widowhood and poverty in rural India: some inferences from household survey data", Journal of Development Economics, Vo. 54, pp. 217-234.

Dreze, J. and G. Kingdon (2001), "School Participation in Rural India", Review of Development Economics, Vol. 5(1), pp. 1-24.

Dubey, A. and S. Gangopadhyay (1998), Counting the Poor: Where are the Poor in India?, Department of Statistics, Government of India.

Lanjouw, P. and M. Ravallion (1995), "Poverty and Household Size”, The Economic Journal, Vol. 105, No. 433, pp. 1415-1434.

Meenakshi, J.V. and R. Ray (2002), "Impact of household size and family composition on poverty in rural India", Journal of Policy Modeling, forthcoming.

Oaxaca, R. (1973), "Male-Female Differentials in Urban Labour Markets”, International Economic Review, Vol. 14, pp. 693-709.

PROBE Team (1999), The Public Report on Basic Education in India, Delhi: Oxford University Press.

Revankar, R. (1971), The Indian Constitution - A Case study of Backward Classes, Rutherford: Fairleigh Dickinson University Press.

Srinivas, M.N. (1962), Caste in Modern India, Bombay: Asia Publishing House.

Yun, Myeong-Su (2000), "Decomposition Analysis for a Binary Choice Model," Working Paper, No. 2000-01, Department of Economics, Rutgers University. 
Table 1

Poverty Rates

\begin{tabular}{|c|c|c|c|c|}
\hline & $\begin{array}{l}\text { Scheduled } \\
\text { Castes }\end{array}$ & $\begin{array}{l}\text { Scheduled } \\
\text { Tribes }\end{array}$ & $\begin{array}{c}\text { Non- } \\
\text { Scheduled }\end{array}$ & All \\
\hline Overall & 49.0 & 49.5 & 32.8 & 38.3 \\
\hline \multicolumn{5}{|l|}{ Age } \\
\hline $20-29$ & 45.3 & 48.6 & 30.2 & 36.5 \\
\hline $30-39$ & 55.9 & 56.6 & 38.2 & 44.7 \\
\hline $40-49$ & 48.9 & 48.2 & 32.1 & 37.6 \\
\hline $50-59$ & 43.9 & 43.0 & 29.8 & 34.2 \\
\hline $60-70$ & 44.3 & 43.4 & 30.0 & 34.1 \\
\hline \multicolumn{5}{|l|}{ Household Size } \\
\hline 1 & 21.5 & 11.3 & 14.7 & 16.0 \\
\hline 2 & 28.9 & 24.8 & 16.7 & 20.9 \\
\hline 3 & 36.0 & 39.1 & 23.5 & 28.4 \\
\hline 4 & 49.3 & 49.5 & 27.5 & 35.2 \\
\hline 5 & 54.1 & 54.5 & 36.2 & 42.3 \\
\hline 6 & 59.3 & 61.6 & 42.2 & 48.2 \\
\hline 7 or more & 65.2 & 64.3 & 44.0 & 50.0 \\
\hline \multicolumn{5}{|l|}{ Education } \\
\hline Not Literate & 53.6 & 54.0 & 40.6 & 46.1 \\
\hline Literate, below primary & 44.5 & 43.8 & 32.5 & 36.9 \\
\hline Literate, below secondary & 38.4 & 40.6 & 27.2 & 30.0 \\
\hline Literate, secondary & 32.8 & 25.3 & 16.3 & 18.7 \\
\hline Literate, higher secondary \& above & 23.3 & 14.9 & 9.9 & 11.6 \\
\hline \multicolumn{5}{|l|}{ Occupation } \\
\hline Self-employed in non-agriculture & 41.9 & 40.8 & 30.1 & 32.9 \\
\hline Self-employed in agriculture & 37.4 & 44.9 & 26.5 & 29.9 \\
\hline Agricultural labor & 58.6 & 58.3 & 50.8 & 54.7 \\
\hline Non agricultural labor & 45.0 & 52.6 & 37.3 & 41.7 \\
\hline Others & 23.3 & 22.6 & 19.4 & 20.2 \\
\hline
\end{tabular}

Notes: a) Observations are weighted by the multipliers assigned to each household in the unit record datafile containing the consumer expenditure survey of the NSS in the $50^{\text {th }}$ round. Source: $50^{\text {th }}$ round (1993/94) of the consumer expenditure survey of the NSS; our calculations. 
Table 2

Sample Means (weighted)

\begin{tabular}{|c|c|c|c|c|c|c|}
\hline & \multicolumn{2}{|c|}{$\begin{array}{c}\text { Scheduled } \\
\text { Castes }\end{array}$} & \multicolumn{2}{|c|}{$\begin{array}{l}\text { Scheduled } \\
\text { Tribes }\end{array}$} & \multicolumn{2}{|c|}{ Non-Scheduled } \\
\hline & Mean & S.D. & Mean & S.D. & Mean & S.D. \\
\hline Poverty Rates & 0.490 & 0.500 & 0.495 & 0.500 & 0.328 & 0.469 \\
\hline \multicolumn{7}{|l|}{ Demographic Control Variables } \\
\hline Age & 42.225 & 12.317 & 41.360 & 11.891 & 43.687 & 12.440 \\
\hline Household Size & 4.691 & 2.175 & 4.774 & 2.145 & 5.013 & 2.435 \\
\hline \multicolumn{7}{|l|}{ Education Variables } \\
\hline Not Literate & 0.679 & 0.467 & 0.695 & 0.460 & 0.482 & 0.500 \\
\hline Literate, below primary & 0.117 & 0.322 & 0.121 & 0.326 & 0.148 & 0.356 \\
\hline Literate, below secondary & 0.156 & 0.363 & 0.142 & 0.350 & 0.250 & 0.433 \\
\hline Literate, secondary & 0.028 & 0.165 & 0.025 & 0.155 & 0.065 & 0.246 \\
\hline Literate, higher secondary $\&$ above & 0.020 & 0.141 & 0.017 & 0.131 & 0.054 & 0.227 \\
\hline \multicolumn{7}{|l|}{ Occupation Variables } \\
\hline Self-employed in non-agriculture & 0.106 & 0.307 & 0.060 & 0.238 & 0.146 & 0.353 \\
\hline Agricultural labor & 0.529 & 0.499 & 0.395 & 0.489 & 0.238 & 0.426 \\
\hline Non-agricultural labor & 0.106 & 0.308 & 0.100 & 0.300 & 0.070 & 0.255 \\
\hline Self-employed in agriculture & 0.195 & 0.396 & 0.390 & 0.488 & 0.438 & 0.496 \\
\hline Others & 0.064 & 0.245 & 0.055 & 0.227 & 0.107 & 0.309 \\
\hline Number of Observations & \multicolumn{2}{|c|}{12,213} & \multicolumn{2}{|c|}{9,861} & \multicolumn{2}{|c|}{42,213} \\
\hline
\end{tabular}


Table 3

The Determinants of Poverty: Probit Analysis

\begin{tabular}{|c|c|c|c|c|c|c|}
\hline \\
\hline & \multicolumn{2}{|c|}{ Scheduled Castes } & \multicolumn{2}{|c|}{ Scheduled Tribes } & \multicolumn{2}{|c|}{ Non Scheduled } \\
\hline & (1) & $(2)$ & (3) & (4) & $(5)$ & $(6)$ \\
\hline Intercept & $\begin{array}{c}-0.897 \\
(0.0034)\end{array}$ & $\begin{array}{c}-0.707 \\
(0.0036)\end{array}$ & $\begin{array}{c}-1.040 \\
(0.0049)\end{array}$ & $\begin{array}{c}-1.703 \\
(0.0062)\end{array}$ & $\begin{array}{c}-0.843 \\
(0.0021)\end{array}$ & $\begin{array}{c}-0.757 \\
(0.0022)\end{array}$ \\
\hline \multicolumn{7}{|c|}{ DEMOGRAPHIC CONTROL VARIABLES } \\
\hline Age & $\begin{array}{c}-0.027 \\
(0.0002)\end{array}$ & $\begin{array}{c}-0.034 \\
(0.0002)\end{array}$ & $\begin{array}{c}-0.024 \\
(0.0002)\end{array}$ & $\begin{array}{c}-0.027 \\
(0.0002)\end{array}$ & $\begin{array}{c}-0.023 \\
(0.0001)\end{array}$ & $\begin{array}{c}-0.028 \\
(0.0001)\end{array}$ \\
\hline Age Square & $\begin{array}{c}0.020 \\
(0.0002)\end{array}$ & $\begin{array}{c}0.027 \\
(0.0002)\end{array}$ & $\begin{array}{c}0.014 \\
(0.0003)\end{array}$ & $\begin{array}{c}0.016 \\
(0.0003)\end{array}$ & $\begin{array}{c}0.015 \\
(0.0001)\end{array}$ & $\begin{array}{c}0.021 \\
(0.0001)\end{array}$ \\
\hline Household size & $\begin{array}{c}0.329 \\
(0.0004)\end{array}$ & $\begin{array}{c}0.364 \\
(0.0004)\end{array}$ & $\begin{array}{c}0.424 \\
(0.0006)\end{array}$ & $\begin{array}{c}0.461 \\
(0.0006)\end{array}$ & $\begin{array}{c}0.304 \\
(0.0002)\end{array}$ & $\begin{array}{c}0.322 \\
(0.0002)\end{array}$ \\
\hline Household size squared & $\begin{array}{c}-0.013 \\
(0.0000)\end{array}$ & $\begin{array}{c}-0.014 \\
(0.0000)\end{array}$ & $\begin{array}{c}-0.021 \\
(0.0000)\end{array}$ & $\begin{array}{c}-0.022 \\
(0.0000)\end{array}$ & $\begin{array}{c}-0.013 \\
(0.0000)\end{array}$ & $\begin{array}{c}-0.013 \\
(0.0000)\end{array}$ \\
\hline \multicolumn{7}{|c|}{ EDUCATION VARIABLES - REFERENCE GROUP: 'NOT LITERATE' } \\
\hline Literate, below primary & $\begin{array}{c}-0.260 \\
(0.0008)\end{array}$ & $\begin{array}{c}-0.290 \\
(0.0009)\end{array}$ & $\begin{array}{c}-0.309 \\
(0.0012)\end{array}$ & $\begin{array}{c}-0.345 \\
(0.0012)\end{array}$ & $\begin{array}{c}-0.247 \\
(0.0005)\end{array}$ & $\begin{array}{c}-0.301 \\
(0.0005)\end{array}$ \\
\hline Literate, below secondary & $\begin{array}{c}-0.439 \\
(0.0008)\end{array}$ & $\begin{array}{c}-0.491 \\
(0.0008)\end{array}$ & $\begin{array}{c}-0.390 \\
(0.0011)\end{array}$ & $\begin{array}{c}-0.435 \\
(0.0012)\end{array}$ & $\begin{array}{c}-0.382 \\
(0.0004)\end{array}$ & $\begin{array}{c}-0.458 \\
(0.0004)\end{array}$ \\
\hline Literate, secondary & $\begin{array}{c}-0.517 \\
(0.0017)\end{array}$ & $\begin{array}{c}-0.549 \\
(0.0018)\end{array}$ & $\begin{array}{c}-0.715 \\
(0.0027)\end{array}$ & $\begin{array}{c}-0.716 \\
(0.0028)\end{array}$ & $\begin{array}{c}-0.726 \\
(0.0008)\end{array}$ & $\begin{array}{c}-0.805 \\
(0.0008)\end{array}$ \\
\hline $\begin{array}{l}\text { Literate, higher secondary \& } \\
\text { above }\end{array}$ & $\begin{array}{c}-0.729 \\
(0.0021)\end{array}$ & $\begin{array}{c}-0.791 \\
(0.0022)\end{array}$ & $\begin{array}{l}-1.018 \\
(0.0036)\end{array}$ & $\begin{array}{c}-0.969 \\
(0.0037)\end{array}$ & $\begin{array}{c}-1.020 \\
(0.0010)\end{array}$ & $\begin{array}{c}-1.113 \\
(0.0010)\end{array}$ \\
\hline \multicolumn{7}{|c|}{ OCCUPATION VARIABLES - REFERENCE GROUP: 'OTHERS' } \\
\hline $\begin{array}{l}\text { Self-employed in non- } \\
\text { agriculture }\end{array}$ & $\begin{array}{c}0.317 \\
(0.0014)\end{array}$ & $\begin{array}{c}0.265 \\
(0.0015)\end{array}$ & $\begin{array}{c}0.264 \\
(0.0024)\end{array}$ & $\begin{array}{c}0.241 \\
(0.0025)\end{array}$ & $\begin{array}{c}0.037 \\
(0.0007)\end{array}$ & $\begin{array}{c}0.049 \\
(0.0007)\end{array}$ \\
\hline Self-employed in agriculture & $\begin{array}{c}0.130 \\
(0.0013)\end{array}$ & $\begin{array}{c}0.075 \\
(0.0014)\end{array}$ & $\begin{array}{c}0.278 \\
(0.0020)\end{array}$ & $\begin{array}{c}0.255 \\
(0.0020)\end{array}$ & $\begin{array}{c}-0.137 \\
(0.0006)\end{array}$ & $\begin{array}{c}0.107 \\
(0.0006)\end{array}$ \\
\hline Agricultural labor & $\begin{array}{c}0.787 \\
(0.0012)\end{array}$ & $\begin{array}{c}0.740 \\
(0.0013)\end{array}$ & $\begin{array}{c}0.684 \\
(0.0020)\end{array}$ & $\begin{array}{c}0.689 \\
(0.0021)\end{array}$ & $\begin{array}{c}0.574 \\
(0.0007)\end{array}$ & $\begin{array}{c}0.583 \\
(0.0007)\end{array}$ \\
\hline Non-agricultural labor & $\begin{array}{c}0.418 \\
(0.0014)\end{array}$ & $\begin{array}{c}0.435 \\
(0.0015)\end{array}$ & $\begin{array}{c}0.495 \\
(0.0022)\end{array}$ & $\begin{array}{c}0.514 \\
(0.0023)\end{array}$ & $\begin{array}{c}0.247 \\
(0.0008)\end{array}$ & $\begin{array}{c}0.297 \\
(0.0009)\end{array}$ \\
\hline With State Dummies? & No & Yes & No & Yes & No & Yes \\
\hline Log Likelihood & -15222311 & -14334263 & -7747445 & -7085045 & -41014760 & -38294722 \\
\hline
\end{tabular}

Notes: a) Observations have been weighted by individual household multiplier. b) Dependent variable equals 1 if the household is below the poverty line. c) Standard Errors in parentheses. d) all coefficient estimates are significant at .01 level. 
Table 4

Decomposition of the 16.2\% Gap in Poverty Between Scheduled Castes vs. Non-Scheduled Aggregate and Sub-Aggregate Effects

\begin{tabular}{|c|c|c|c|c|}
\hline \multicolumn{5}{|c|}{ Without State Dummies } \\
\hline & \multicolumn{2}{|c|}{ Characteristics Effect } & \multicolumn{2}{|c|}{ Coefficients Effect } \\
\hline & Estimate & Share $(\%)$ & Estimate & Share $(\%)$ \\
\hline Aggregate Effects & 0.094 & 58.0 & 0.068 & 42.0 \\
\hline Intercept & & & -0.019 & -11.9 \\
\hline \multicolumn{5}{|c|}{ Demographic Control Variables } \\
\hline Age & 0.004 & 2.7 & -0.031 & -19.6 \\
\hline Household Size & -0.015 & -9.0 & 0.044 & 26.8 \\
\hline Education & 0.036 & 21.6 & 0.000 & 0.3 \\
\hline Occupation & 0.069 & 42.7 & 0.074 & 46.4 \\
\hline
\end{tabular}

With State Dummies

\begin{tabular}{|l|c|c|c|c|}
\hline Aggregate Effects & 0.091 & 56.3 & 0.070 & 43.7 \\
\hline Intercept & & & -0.016 & -9.8 \\
\hline Demographic Control Variables & \multicolumn{5}{|l|}{} \\
\hline \multicolumn{1}{|c|}{ Age } & 0.004 & 2.6 & -0.037 & -23.0 \\
\hline \multicolumn{1}{|c|}{ Household Size } & -0.014 & -8.7 & 0.058 & 35.7 \\
\hline Education & 0.037 & 22.8 & 0.003 & 1.9 \\
\hline Occupation & 0.062 & 38.6 & 0.050 & 30.8 \\
\hline Net Effect of State Dummies & 0.002 & -1.0 & -0.019 & -11.6 \\
\hline
\end{tabular}


Table 5

Decomposition of the 16.7\% Gap in Poverty Between Scheduled Tribes vs. Non-Scheduled Aggregate and Sub-Aggregate Effects

Without State Dummies

\begin{tabular}{|c|c|c|c|c|}
\hline & \multicolumn{2}{|c|}{ Characteristics Effect } & \multicolumn{2}{|c|}{ Coefficients Effect } \\
\hline & Estimate & Share(\%) & Estimate & Share $(\%)$ \\
\hline Aggregate Effects & 0.068 & 40.8 & 0.099 & 59.2 \\
\hline Intercept & ---- & ---- & -0.071 & -42.8 \\
\hline \multicolumn{5}{|c|}{ Demographic Control Variables } \\
\hline Age & 0.006 & 3.8 & -0.039 & -23.0 \\
\hline Household Size & -0.009 & -5.2 & 0.123 & 73.9 \\
\hline Education & 0.036 & 22.5 & -0.003 & -1.7 \\
\hline Occupation & 0.032 & 19.7 & 0.088 & 52.8 \\
\hline
\end{tabular}

With State Dummies

\begin{tabular}{|l|c|c|c|c|}
\hline & \multicolumn{2}{|c|}{ Characteristics Effect } & \multicolumn{2}{c|}{ Coefficients Effect } \\
\hline & Estimate & Share(\%) & Estimate & Share(\%) \\
\hline Aggregate Effects & 0.043 & 25.7 & 0.124 & 74.3 \\
\hline Intercept & - & - & -0.295 & -176.2 \\
\hline Demographic Control Variables & \multicolumn{4}{|c|}{} \\
\hline \multicolumn{1}{|c|}{ Age } & 0.007 & 4.2 & -0.011 & -7.1 \\
\hline \multicolumn{1}{|c|}{ Household Size } & -0.009 & -5.7 & 0.136 & 81.7 \\
\hline Education & 0.044 & 26.6 & 0.001 & 0.5 \\
\hline Occupation & 0.034 & 20.5 & 0.067 & 40.3 \\
\hline Net effect of state dummies & -0.033 & -19.9 & 0.360 & 135.1 \\
\hline
\end{tabular}

Note: Share is percentage share of difference in probability of being poor. 
Table 6

Decomposition of the 16.2\% Gap in Poverty Between Scheduled Castes vs. Non-Scheduled Individual Effects

(without state dummies)

\begin{tabular}{|c|c|c|c|c|}
\hline & \multicolumn{2}{|c|}{ Characteristics Effect } & \multicolumn{2}{|c|}{ Coefficients Effect } \\
\hline & Estimate & Share $(\%)$ & Estimate & Share $(\%)$ \\
\hline Total & 0.094 & 58.0 & 0.068 & 42.0 \\
\hline Intercept & & & -0.019 & -11.9 \\
\hline \multicolumn{5}{|c|}{ DEMOGRAPHIC CONTROL VARIABLES } \\
\hline Age & 0.011 & 6.8 & -0.061 & -38.0 \\
\hline Age Square & -0.007 & -4.1 & 0.030 & 18.4 \\
\hline Household size & -0.033 & -20.1 & 0.043 & 26.3 \\
\hline Household size squared & 0.018 & 11.1 & 0.001 & 0.5 \\
\hline \multicolumn{5}{|c|}{ EDUCATION VARIABLES - REFERENCE GROUP: 'NOT LITERATE' } \\
\hline Literate, below primary & 0.003 & 1.6 & -0.001 & -0.3 \\
\hline Literate, below secondary & 0.012 & 7.4 & -0.003 & -1.9 \\
\hline Literate, secondary & 0.009 & 5.5 & 0.002 & 1.3 \\
\hline $\begin{array}{l}\text { Literate, higher secondary } \\
\& \text { above }\end{array}$ & 0.012 & 7.2 & 0.002 & 1.3 \\
\hline \multicolumn{5}{|c|}{ OCCUPATION VARIABLE - REFERENCE GROUP: 'OTHERS' } \\
\hline $\begin{array}{l}\text { Self-employed in non- } \\
\text { agriculture }\end{array}$ & -0.000 & -0.3 & 0.010 & 6.5 \\
\hline $\begin{array}{l}\text { Self-employed in } \\
\text { agriculture }\end{array}$ & 0.011 & 6.9 & 0.018 & 11.4 \\
\hline Agricultural labor & 0.055 & 34.3 & 0.040 & 24.5 \\
\hline Non-agricultural labor & 0.003 & 1.8 & 0.006 & 4.0 \\
\hline
\end{tabular}

Note: Share is percentage share of difference in probability of being poor. 
Table 7

Decomposition of the 16.7\% Gap in Poverty Between Scheduled Tribes vs. Non-Scheduled Individual Effects

(without state dummies)

\begin{tabular}{|c|c|c|c|c|}
\hline & \multicolumn{2}{|c|}{ Characteristics Effect } & \multicolumn{2}{|c|}{ Coefficients Effect } \\
\hline & Estimate & Share $(\%)$ & Estimate & Share $(\%)$ \\
\hline Aggregate Effect & 0.068 & 40.8 & 0.099 & 59.2 \\
\hline Intercept & & & -0.071 & -42.8 \\
\hline \multicolumn{5}{|c|}{ DEMOGRAPHIC CONTROL VARIABLES } \\
\hline Age & 0.017 & 10.2 & -0.026 & -15.4 \\
\hline Age Square & -0.011 & -6.4 & -0.013 & -7.6 \\
\hline Household size & -0.024 & -14.2 & 0.206 & 123.6 \\
\hline Household size squared & 0.015 & 9.0 & -0.083 & -49.7 \\
\hline \multicolumn{5}{|c|}{ EDUCATION VARIABLES - REFERENCE GROUP: 'NOT LITERATE' } \\
\hline Literate, below primary & 0.002 & 1.3 & -0.003 & -1.6 \\
\hline Literate, below secondary & 0.013 & 8.1 & -0.000 & -0.2 \\
\hline Literate, secondary & 0.009 & 5.7 & 0.000 & 0.1 \\
\hline $\begin{array}{l}\text { Literate, higher secondary \& } \\
\text { above }\end{array}$ & 0.012 & 7.4 & 0.000 & 0.0 \\
\hline \multicolumn{5}{|c|}{ OCCUPATION VARIABLE - REFERENCE GROUP: 'OTHERS' } \\
\hline $\begin{array}{l}\text { Self-employed in non- } \\
\text { agriculture }\end{array}$ & -0.001 & -0.6 & 0.005 & 3.0 \\
\hline Self-employed in agriculture & 0.002 & 1.3 & 0.058 & 35.0 \\
\hline Agricultural labor & 0.029 & 17.6 & 0.016 & 9.4 \\
\hline Non-agricultural labor & 0.002 & 1.4 & 0.009 & 5.4 \\
\hline
\end{tabular}

Note: Share is percentage share of difference in probability of being poor. 